Josef van Ess*

\title{
Unfertige Studien II: Bemerkungen zum Korankommentar des Așamm
}

DOI 10.1515/asia-2016-1512

Abstract: Abu Bakr al-Asamm's (d. 200/816 or 201/817) commentary of the Qur'an is one of the oldest of its genre. It originated in Basra but seems to have become a "book" only when, in the middle of the 3rd century H., it was transferred from Baghdad to Eastern Iran. There it was used by a number of authors, Sunni as well as Shii. The greatest number of quotations is found in Maturidi's (d. 333/944 ?) Ta'wilat. The article deals with the material found in this source, its tendency as well as its relationship to quotations in later authors up to Fakhr al-Din al-Razi (d. $606 / 1210$ ). The work has not survived, and we can only speculate where and for how long several copies, complete or incomplete survived.

Keywords: Qur'anic exegesis, Mu'tazila, Islamic theology in Eastern Iran and Central Asia, Maturidi, Fakhr al-Din al-Razi, Tabrisi, Muhammad al-Tusi

$\mathrm{Zu}$ dem Korankommentar des Abū Bakr 'Abdarraḥmān b. Kaisān al-Aṣamm (2. Jh. H.) habe ich mich vor jetzt mehr als 20 Jahren kurz geäußert. ${ }^{1}$ Gestützt habe ich mich dabei auf iranische Quellen, in denen das Werk noch in späterer Zeit herangezogen wird: Abū l-Mu'īn an-Nasafīs (gest. 508/1114) Tabșirat al-adilla, Amīnaddīn aț-Ṭabrisīs (gest. 548/1154) Mağma' al-bayān und Fahraddīn ar-Rāzīs (gest. 606/1210) Mafātīḥ al-ġaib. ${ }^{2}$ Haḍir Muhammad Nabhā hat diesen Ansatz weiterverfolgt, indem er die Zitate aus Ṭabrisī und Rāzī systematisch sammelte und i. J. 2006 unter dem Titel Tafsīr Abì Bakr al-Așamm herausbrachte. ${ }^{3}$ Dabei sind auch einige wenige Zitate aus

1 TG: 2: 403-407.

2 Vgl. die Texte XIII 17-21A in TG: 5: 199-203.

3 Nabhā 2006; zusammen mit dem Tafsīr des Abū Muslim Muḥammad b. Baḥr al-Iṣfahānī (254/868-311/934), als Nr.1 und 2 einer geplanten Mausū'at tafāsīr al-Mu'tazila. Der Autor hat an der Libanesischen Universität mit einer Arbeit über Hišām b. al-Ḥakam unter R. asSaiyid promoviert. - Das Todesdatum des Așamm wird auf dem Titelblatt mit „ca. 225“ viel zu spät angesetzt; nach dem Fihrist des Ibn an-Nadīm ist er 200/816 oder 201/817 gestorben (Ibn an-Nadìm 2009: 1: 594, 14).

*Corresponding author: Josef van Ess, Liegnitzer Strasse 11, 72072 Tübingen, Germany. E-mail: josef.van-ess@uni-tuebingen.de 
Muhammad aț-Ṭūsīs (gest. 459 oder 460/1066-67) Tibyān fì tafsīr al-Qur'ān zu ihrem Recht gekommen; ${ }^{4}$ sie hatten bei Țabrisī nachgewirkt.

Ganz übersehen aber hat Nabhā, daß lange vor diesen Zeugen ein weiterer Gewährsmann, nämlich Māturīdī (gest. 333/944 ?) in seinen Ta’wīlāt al-Qur'ān, sich verhältnismäßig häufig auf Așamm bezieht. Zwar war bis zum Jahre 2006 nur der erste Band dieses umfangreichen Werkes im Druck zugänglich; ${ }^{5}$ aber man wußte seit je von zahlreichen Handschriften, die größere Stücke oder gar den vollständigen Text enthielten. ${ }^{6}$ Manfred Götz hat zum erstenmal Inhalt und Intention des Werkes beschrieben. ${ }^{7}$ Aber das Interesse hielt sich seit je in Grenzen; Māturīdī hatte in dem Weltbild arabischsprachiger Sunniten kaum je einen Platz gefunden. Er hatte in Samarqand gelebt, und sein Erbe, hanafitisch geprägt, hatte erst in osmanischer Zeit außerhalb dieser Welt Fuß gefaßt, in Anatolien, wo hanafitische Juristen aus Zentralasien seit der Zeit der Rumseldschuken an Einfluß gewonnen hatten. Daß man es hier mit einer speziell gefärbten sunnitischen Orthodoxie zu tun hatte, ist in der Frühzeit des osmanischen Vordringens nur dem Ägypter Tāğaddīn as-Subkī (727/1327-771/ 1370) aufgefallen; er schrieb darüber ein kurzes Lehrgedicht, das er in seine Tabaqāt aš-Šâfi ìya aufnahm. ${ }^{8}$ Im großen und ganzen aber blieb die arabische Welt gegenüber diesem Kulturtransfer immun; für sie ging weiterhin alle sunnitische Orthodoxie von Aš'arī aus.

Nun hat sich die Situation jedoch insofern geändert, als in der Türkei, wo die Tradition Māturīdīs weiterhin lebendig ist, ${ }^{9}$ mittlerweile eine Gesamtausgabe der Ta'wīlāt erschienen ist, in 17 Bänden, die durch gute Indices erschlossen werden. ${ }^{10}$ Dadurch ist die Zahl der Belege für Așamms Kommentar erheblich gestiegen. ${ }^{11}$ Um deutlich $\mathrm{zu}$ machen, wie sehr sich die Grundlage für unser Urteil

4 Vgl. Nabhā 2006: 48, 67 und 97.

5 In zwei Editionen: a) Māturīdī 1971 b) Māturīdī 1983. Der Titel lautet dort Ta’wīlāt ahl as-sunna statt Ta'wīlāt al-Qur'ān.

6 Vgl. Sezgin 1967: 605.

7 Māturīdī und sein Kitāb Ta'wīlāt al-Qur'ān, Götz 1965; dort S. 63 ff. auch schon eine Beschreibung der in der Türkei erhaltenen Handschriften. Eine englische Übersetzung dieses Aufsatzes findet sich in: Götz 1999 > Götz 2013: 3: 283-313. Vgl. damit die Ausführungen bei Rudolph 1997: 202 ff. 8 Dazu näher Badeen 2008, wo dieses Gedicht, die Nūnīya, mit einem erklärenden Apparat abgedruckt ist (S. 2-18 des arabischen Teils); zum Autor vgl. die deutsche Einleitung, S. 10-19. 9 Badeen ediert in seinem Buch sechs weitere Texte aus osmanischer Zeit, in denen Māturīdīya und Aš‘arīya miteinander verglichen werden.

10 Māturīdī 2005-2011, herausgegeben von einem Team unter der Oberaufsicht von Bekir Topaloğlu.

11 Merkwürdigerweise wird auch in dieser an sich mustergültigen Ausgabe das Todesdatum des Așamm in den Anmerkungen mehrfach mit „ca. 225/840“ angegeben. Derselbe Fehler findet sich schon bei Frolow 1997: 71, Anm. 31 (nachgedruckt in: Frolow 2013: 1: 216). Zugrunde liegt 
verbreitert hat, beginne ich mit einer Übersicht über diejenigen Koranverse, zu denen Māturīdī auf eine Stellungnahme Așamms verweist. Die von Nabhā gesammelten Belege füge ich in eckigen Klammern und kursiv gesetzt hinzu. Bei ihnen habe ich insofern differenziert, als das aus Țabrisī entnommene Material durch einen Asteriskus gekennzeichnet ist. Țūsī (der šaih aț-țā'ifa), der auf Tabrisī eingewirkt hat, wird zu Sure 2: 234, 6: 68 und 59: 10 herangezogen. Alles andere stammt aus Fahraddīn ar-Rāzì. Dieser hat manchmal dieselben Stellen aufgegriffen wie Māturīdī; darauf ist jeweils in den Fußnoten hingewiesen.

Sure 2: Vers $\left[2,6^{*}, 7^{*}, 8^{* 12} 11\right] 17,,^{13}\left[19^{*}, 26\right], 31,32,{ }^{14} 34,{ }^{15}\left[43,45^{*}, 58,63\right.$, $\left.73^{*}, 76,80,88,99^{*}, 102,106,117\right], 118\left[119^{*}, 129^{*}, 130^{*}, 131,144,145,154^{*}, 158^{*}\right.$, $159,174,175,179,184,185,187,189,195,221,222,234^{*}, 235,245^{*}, 247,253,254$, 258, 261, 265, 277].

Sure 3: Vers [3], 8, [11*, 72, 79], 81, [84, 98*, 106, 121, 124, 133, 167*, 169, 172, 200].

Sure 4: Vers $\left[1{ }^{16} 19^{*}, 23\right], 24,[33], 48,[53,64], 83,85,92,{ }^{17}[148]$.

Sure 5: Vers 3, 27, [31*], 33, 48, 89, [93, 106*].

Sure 6: Vers 6, [32], 33, 64, 65, [68], 74, [92, 98], 108, 109, 120, 148, 152, 154, 155, 161.

Sure 7 : Vers $4,10,16,26,{ }^{18} 32,37,42,50,52,54,58,89,90,104,132,143,{ }^{19}$ 154, 155, 167, 169, [187], 189, [190* 206].

Sure 8: Vers 21, 45, 58, 67, 68, [72*].

Sure 9: Vers $1,3,{ }^{20} 6,[13,15], 24,\left[36^{*}, 39,40,58\right], 60,\left[67^{*}, 86\right], 101,104,122$, $124 \mathrm{f}$.

Sure 10: Vers [2*], 5, [12, 15, 22*, 26], 61, [62], 71, 94.

eine vage Bemerkung des Ibn Ḥağar al-'Asqalānī 1912: 3: 427, 5), wonach Așamm „zur țabaqa des Abū l-Hudail gehörte“. Den Fihrist des Ibn Nadīm dagegen, wo das genauere Datum sich findet (s. o. Anm. 3), benutzte man wohl nur in der alten Ausgabe von Flügel. Darin war der Abschnitt über die Mu'tazila noch nicht enthalten; er wurde erst von J. Fück in Indien entdeckt und herausgegeben. - Für Saleh 2004: 246 ist Așamm „ca. 190/805“ gestorben.

12 Von mir in TG: 5: 199, Text XIII 17 übersetzt; Nabhā hat die Stelle übersehen.

13 Übersetzt in TG: 5: 200, Text XIII 18.

14 Übersetzt in TG: 5: 201, Text XIII 19.

15 Übersetzt in TG: 5: $201 \mathrm{f}$., Text XIII 20. Auch bei Nabhā 2006 nach Ṭabrisī.

16 Nicht bei Nabhā 2006; nach den Mafātịh al-ġaib des Faḩraddīn ar-Rāzī übersetzt in TG: 5: 202, Text XIII 21.

17 Auch bei Nabhā 2006, nach Faḩraddīn ar-Rāzī.

18 Auch bei Nabhā 2006, nach Faḩraddīn ar-Rāzī.

19 Später auch in der Tabșirat al-adilla des Abū l-Mu'īn an-Nasafï; danach übersetzt in TG: 5: 202: Text XIII 21A.

20 Auch bei Nabhā 2006, nach Fahraddīn ar-Rāzī. 
Sure 11: Vers [7], 52, ${ }^{21} 92$.

Sure 12: Vers [20*], 33, 39, [94*], 101.

Sure 13: Vers [3, 4, 5, 24], 32, 33, [39].

Sure 14: Vers 2, [5], 9, [10], 21, 22.

Sure 15: Vers $32 \mathrm{f} .$, 39, 44, 52, 60, 70.

Sure 16: Vers [9], 14, 23, 37, 55, 62, 68, 70, 71, 72, 88, [89], 90, [91], 92, 93, 94, 97, 104, 109, 111, 124, 125.

Sure 17: Vers 12, 23, 29, 31, [41], 45, 55, 57, 58, 72, 85, [86*], 110.

Sure 18: Vers $\left[1^{*}\right], 7,22,28,29,40,52,\left[65,71^{*}\right], 77,82,109$.

Sure 19: Vers $1,5,{ }^{23} 12,\left[16^{*}\right], 21,23,24,27,\left[47^{*}\right], 52,\left[75^{*}\right], 83,86,97$.

Sure 20: Vers 8.

Sure 21: Vers [78].

Sure 22: Vers [30], [58].

Sure 23: Kein Eintrag.

Sure 24: Vers [35].

Sure 25: Vers [48], [63].

Sure 26-36: Kein Eintrag.

Sure 37: Vers 34.

Sure 38: Kein Eintrag.

Sure 39: Vers 3.

Sure 40-47: Kein Eintrag.

Sure 48: Vers 8.

Sure 49-50: Kein Eintrag.

Sure 51: Vers 22, 28, 47, 50 (zweimal), 52, 54, 59.

Sure 52: Vers 21, 23, 25, 37.

Sure 53: Vers 1, 12, 17, 26, 32.

Sure 54: Vers 1.

Sure 55: Vers 21, 32, 78.

Sure 56: Vers 35, 43, [46*], 55, 61, 65, 69, 82.

Sure 57: Vers [19]

Sure 59: Vers $\left[10^{*}\right]$.

Sure 60: Vers 4.

Sure 62: Vers 2.

Sure 63: Vers 6.

Sure 64: Vers 11.

Sure 65: Vers 6.

21 Auch bei Nabhā 2006, nach Fahraddīn ar-Rāzī.

22 Auch bei Nabhā 2006, nach Fahrraddīn ar-Rāzī.

23 Auch bei Nabhā 2006, nach Fahrraddīn ar-Rāzì. 


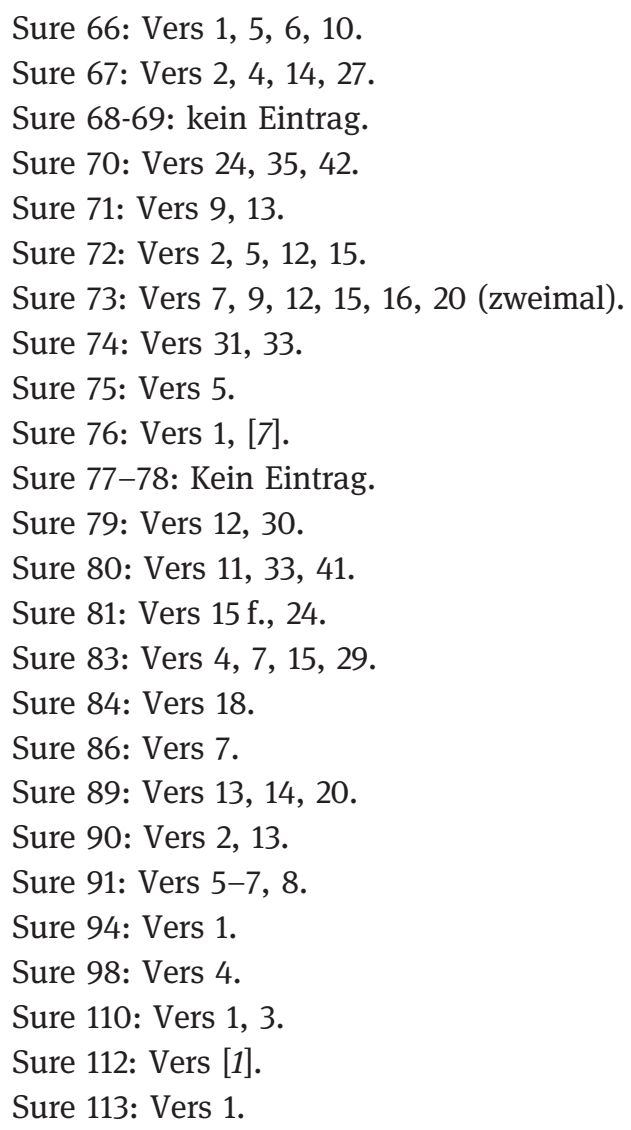

Aus diesem Befund lassen sich erste Schlüsse ziehen. Zwar ist das Verhältnis der Quellen zueinander vorläufig nicht befriedigend zu klären. Jedoch mag man vermuten, daß Rāzī, mit dem die Reihe unserer Textzeugen abbricht, gelegentlich die Werke seiner Vorgänger eingesehen hat, soweit sie ihm zugänglich waren (etwa den Mağma' al-bayān des Ṭabrisī zu Sure 3: 11, 3: 167 oder 4: 19); es würde sich dort also um Sekundärzitate handeln. Wichtiger ist allerdings, daß die Belege aus Nabhās Sammlung schon von Sure 4 an stark abnehmen. Sie stammen vornehmlich aus Faḩraddīn ar-Rāzīs Korankommentar, und Rāzī ist mit seinen Mafātīḥ algaib nie ganz fertig geworden. Fünf Jahre vor seinem (verhältnismäßig frühen) Tod, $601 / 1205$, hatte er sich gerade bis zum Ende von Sure 8 vorgearbeitet. ${ }^{24}$ Damals

24 Faḩr ad-Dīn ar-Rāzī 1862-1872: 3: 408, 14 f. (zitiert in meiner Erkenntnislehre des 'Aḍudaddīn al-İci, van Ess, 1966: 147); vgl. jetzt Altaş 2013: 144. 
lebte er im Herrschaftsbereich der Ġūriden, im heutigen Afghanistan; sie waren seit etwa 595/1198-99 seine Gönner. ${ }^{25}$ Wir wissen nicht, wo er ein Exemplar von Aṣamms Tafsīr vorfand, das er regelmäßig hätte zu Rate ziehen können; er ist immer viel gereist. Man könnte an Herat denken, wo der Gūride Ġiyātaddīn Muhammad (reg. 558/163-599/1203) eine Madrasa für ihn hatte errichten lassen; sie lag in der Nähe der Hauptmoschee und war vermutlich mit einer guten Bibliothek ausgestattet. ${ }^{26}$ Rāzī hätte das Werk wohl einmal für längere Zeit zur Hand haben müssen; daß er sich irgendwo im Vorübergehen schnell ein paar Notizen machte, ist angesichts der Zahl der Einträge $\mathrm{zu}$ den ersten Suren unwahrscheinlich. Kurz darauf ist er in einem Schub bis zu Sure 18 gekommen;

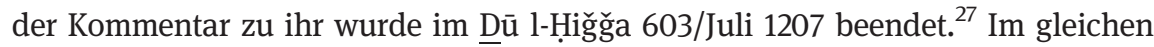
Jahr wurden dann die Suren $37-46$ bearbeitet, diesmal in der Tat in Herat, ${ }^{28}$ nur daß gerade dieser Abschnitt von Rāzīs Kommentar kaum Zitate aus Aṣamm enthält.

Vor allem ist zu berücksichtigen, daß Rāzī sich, aus welchen Gründen auch immer, zu Anfang nicht an die normale Reihenfolge der Suren gehalten hat; vielmehr hat er sich mit den Suren 104, 94, 87, 78 und 67 schon vorher befaßt. $^{29}$ Obgleich er also mit seinem Kommentar nie fertig geworden und das Werk in der folgenden Generation ergänzt worden ist, ${ }^{30}$ scheint es dennoch möglich, daß die wenigen Belege, die wir aus den späten Suren haben, ${ }^{31}$ aus seiner eigenen Feder stammen. Da lohnt es sich dann, darauf hinzuweisen, daß er auch einmal in

25 Griffel 2007: 334 und 340. Am 1. Rabī' II 595/31. Januar 1199 hatte er Sure 3 fertiggestellt, drei Monate später Sure 4. Mit Sure 5 begann er dann nach längerer Unterbrechung Anfang 601/1204 (Griffel, 2007: 325). Dort klagt er darüber, daß die „Ungläubigen“ einen Sieg errungen hätten; im Șafar 601/September 1204 hatten die Qara Hुitay bei Andhūy in der Nähe des Oxus das Heer der Ġūriden geschlagen (Griffel, 2007: 329). Griffels Angaben sind einem grundlegenden Aufsatz von J. Jomier entnommen (Jomier, 1977), der die Entwicklung der Mafātịh al-ġaib sehr übersichtlich darstellt.

26 Griffel 2007: 329. Auch die Hauptmoschee hatte Ġiyātaddīn neu errichten lassen, schon i. J. 597, nachdem sie durch ein Feuer zerstört worden war (Griffel, 2007: 329, Anm. 61).

27 Jomier 1977: 256 f.; Griffel 2007: 325.

28 Jomier 1977: $260 \mathrm{ff}$.

29 Griffel 2007: 325, Anm. 45 nach Lagarde 1996: 51 ff.; vgl. auch Altaş 2013: 144, wonach er i. J. 592 ausgerechnet mit der letzten Sure, nr. 114, angefangen hatte und i. J. 601 schon die Suren 10-14 behandelte, obgleich er an sich erst bei Sure 8 angelangt war.

30 Vgl. Jomier 1980: 467 ff. Die Frage nach dem Autor der Ergänzungen bleibt dort letzten Endes offen. Auch über den Grund läßt sich nur spekulieren. Möglicherweise hat nicht etwa Rāzī selber die Lücke gelassen, sondern das Material ist beim Brand der Hauptmoschee von Herat (s. o. Anm. 26) verloren gegangen.

31 Aus den Suren 57, 59, 76 und 112 (s.o.). 
Samarqand gewesen ist, ${ }^{32}$ wo Māturīdī gelebt hatte; dort hat er sich zwei Jahre aufgehalten. ${ }^{33}$ Allerdings war das schon in der ersten Hälfte der achtziger Jahre des 6. Jh. H., ${ }^{34}$ also zu einer Zeit, in der er die Mafātīh vermutlich noch gar nicht im Blick hatte; er war damals noch auf der Wanderschaft und suchte nach einer festen Stelle. Was sich soweit also mit Sicherheit sagen läßt, ist nur, daß er nicht auf Sekundärzitate aus Așamm zurückgegriffen hat, die ihm in der theologischen Literatur begegneten. Dort nämlich, wo er Așamm für denselben Vers heranzieht wie Māturīdī, geht er normalerweise eigene Wege; es kommt im übrigen, wie aus unserem Conspectus hervorgeht, nur selten vor. ${ }^{35}$

Daß Rāzī überhaupt Așamms Kommentar Beachtung schenkte, ist angesichts des großen zeitlichen Abstands und des völlig anderen intellektuellen Ansatzes erstaunlich. Māturīdī dagegen war von Așamm nur anderthalb Jahrhunderte entfernt und hatte in der Gegend, wo er lebte, auch nur wenig Auswahl. Sein Arabisch war bei weitem nicht so gut wie das Fahraddins; ${ }^{36}$ aber er war nicht so unruhig und hat seine Ta'wīlāt deswegen zu Ende gebracht. Er scheint auch entschlossen gewesen zu sein, Așamm bis zum Abschluß seines Werkes heranzuziehen. Wenn wir dennoch für eine Reihe von Suren keine Belege haben, so dürfte sich dies daraus erklären, daß das Exemplar, das ihm zur Verfügung stand (vermutlich in Samarqand), unvollständig war; wir haben keine Einträge für die Suren 21-36, ${ }^{37} 40-47,49-50$ und 57-59. Allerdings müssen wir damit rechnen, daß gegen Ende der Eifer ohnehin erlahmte, und zwar bei allen Beteiligten, bei Așamm ebenso wie bei Māturīdī. Das ist nämlich auch anderswo der Fall, etwa in Tabarīs umfangreichem Kommentar; man wollte sich nicht wiederholen, und je mehr man zu Anfang schon gesagt hatte, desto weniger ließ sich noch hinzufügen.

32 Vgl. seine Munāzarāt fi bilād Mā warā’ an-nahr (Faḩr ad-Dīn ar-Rāzī, 1966), dort die nr. 16 (S. $59 \S 161 \mathrm{ff}$.).

33 Fah̆r ad-Dīn ar-Rāzī 1966: 54 § 143.

34 Das einzige Datum, das uns die Munāzarāt bieten, ist 582/1186 (zu Beginn der 9. mas'ala; S. $32 \S 78$ ); damals befand er sich in Buhārā. Für das Jahr 580 ist ein Aufenthalt in Sarahs belegt (Griffel, 2007: 320).

35 Grundsätzlich wäre Nabhās Zusammenstellung allerdings anhand des oben (Anm. 29) genannten Index von Lagarde noch einmal zu überprüfen (vgl. Lagarde, 1996: 13 nr. 100 s. n. Ibn Kaisān und vor allem S. 15 nr. 141 s. n. Abū Bakr al-Așamm; auch S. 138 nr. 2090 s. v. Tafsīr al-Așamm). Nabhā hat Lagardes Werk anscheinend nicht zur Hand gehabt.

36 Sein K. at-Tauhīd ist in dieser Hinsicht ein abschreckendes Beispiel. Wenn man die Ta'wīlāt demgegenüber allgemein als leichter verständlich empfand, so hatte dies seinen Grund darin, daß wir es hier mit Nachschriften seiner Schüler zu tun haben (vgl. Rudolph, 1997: 204).

37 Die wenigen Zeugnisse, die wir aus Sure 21-22 und 24-25 haben, stammen nicht aus Māturīdī, sondern aus Rāzì (bei Nabhā). Im übrigen ist auch Rāzī, als er in den Jahren 602 und 603 kontinuierlich an seinen Mafātīh al-gaib arbeitete, von Sure 18 auf Sure 37-46 gesprungen (Altaş, 2013: 144). 
Zudem wissen wir nicht, wie Māturīdīs Kommentar aufgeteilt war, ob in umfangreiche Bände oder in kleinere Faszikel (ğuz'). ${ }^{38}$ Faszikel richteten sich im allgemeinen auch nicht nach den Zäsuren im Text; ihr Ende dürfte also nicht unbedingt mit dem Ende einer Sure zusammengefallen sein. So kann die erste Lücke schon in Sure 20 begonnen haben, die zweite in Sure 39 und die dritte in Sure 48. Auch die fehlenden Eintragungen zu Sure 38 brauchen dann kein Zufall zu sein; diese Lücke hat vielleicht schon in der zweiten Hälfte von Sure 37 begonnen. Allgemein fällt aber auf, daß in dem Tahdīb fi t-tafsīr des Ḥākim al-Ǧišumī (gest. 494/1101) die Zitate aus Așamm ebenfalls nach dem ersten Drittel von Sure 20 aufhören und dann erst wieder bei Sure 38 beginnen. ${ }^{39}$ Man muß also die Möglichkeit in Betracht ziehen, daß Așamms Kommentar schon unvollständig war, als er in Iran ankam. ${ }^{40}$

Vermutlich waren die Abhängigkeitsverhältnisse ohnehin komplizierter. Man sollte nicht unbedingt davon ausgehen, daß nur ein einziger Archetyp von Așamms Werk Ostiran und Zentralasien erreichte. Später gab es gewiß verschiedene Standorte. Die Exemplare, welche Fahraddīn ar-Rāzī zur Verfügung standen, sahen offenbar ganz anders aus als Mātūrīdīs Vorlage und waren doch vermutlich auch schon seit Jahrhunderten an ihrem Platz. Bevor wir nicht weitere Belege in Händen halten, sollten wir uns darum bei unseren Spekulationen zurückhalten. Vor allem werden wir warten müssen, bis Ǧišumīs Tahdīb im Druck erscheint; denn auch dort steht Așamm noch sehr im Vordergrund. ${ }^{41}$ Der Schauplatz unserer Untersuchungen bleibt allerdings weiterhin der Osten der islamischen Welt. Zwar war der Kommentar in Bașra entstanden; aber dort war ihm die Bodenhaftung anscheinend schon früh abhanden gekommen. Die Stadt verlor seit der Gründung Bagdads ohnehin an Bedeutung. Așamms Tafsīr war Teil jener exegetischen Tradition, die durch Ḥasan al-Bașrī (gest. 110/728) begründet worden war. Hasan wird bei Māturīdī immer wieder einmal im Zusammenhang mit Așamm zitiert, nicht im Sinne eines Lehrer-Schüler-Verhältnisses, ${ }^{42}$ sondern weil beide von außen her gesehen eine gemeinsame Linie zu vertreten schienen. ${ }^{43}$ Sie waren zwar im Einzelnen häufig

38 Zur Länge eines ğuz' vgl. Gacek 2001: 23.

39 Notiert bei Gimaret 1994: 25, Anm. 6. Dazu jetzt Mourad 2012: 374, Anm. 30, wo aber nur darauf hingewiesen wird, daß von Ǧišumīs Kommentar weitere Teile erhalten sind, die die Lücke füllen. Așamm kommt bei Mourad gar nicht in den Blick.

40 Unsere Zusammenstellung bringt mit Bezug auf den genannten Abschnitt nur zu Sure 24 und 25 einige wenige Einträge; das sind aber interessanterweise Stellen, wo Rāzī (und nicht Māturīdī) auf Aṣamm Bezug nimmt.

41 TG: 2: 404.

42 Dazu war auch der zeitliche Abstand $\mathrm{zu}$ groß.

43 Vgl. etwa Ta’wīlāt, Māturīdī 2005-2011: 1: 83, $3 \mathrm{f}$. (zu Sure 2:34 und der Frage, ob Satan ursprünglich ein Engel war); Māturīdī 2005-2011: 4: 209, 1 ff. (zu Sure 5:33); Māturīdī 
verschiedener Meinung; ${ }^{44}$ aber sie folgten beide qadaritischen Prinzipien, die in Bașra seit der späten Umaiyadenzeit sehr an Boden gewonnen hatten. Hasan war in dieser Hinsicht noch sehr gemäßigt gewesen; ${ }^{45}$ zudem trug er seine Gedanken den Schülern nur mündlich vor. ${ }^{46}$ Așamms Tafsīr dagegen nahm auf die Dauer die Gestalt eines selbständigen Buches an, vermutlich noch nicht in Bașra, wo das Material (vielleicht zusammen mit den auf Hasan alBașrī’s Exegese zurückgehenden Notizen) nur "in der Schule für die Schule"47 kursierte, sondern in Bagdad, wo 'Alī b. Muslim aț-Ṭūsī (gest. 253/867) ${ }^{48}$ es aus dem Munde der “Genossen” (așhāa) Așamms übernahm und in seine horāsānische Heimat transferierte. ${ }^{49}$ Aus dem Irak ist uns dann kein weiterer rāwī mehr bekannt.

Auch die bașrischen "Genossen" sind namentlich nicht $\mathrm{zu}$ fassen. Wir wissen nicht, ob dort jemand das Material geordnet und daraus einen durchgehenden Kommentar erstellt hat. Wiederum könnte 'Alī b. Muslim derjenige gewesen sein, der sich als Erster an diese Arbeit machte. Aber ein Tafsīr im

2005-2011: 5: 246, -5f. (zu 6:148); Māturīdī 2005-2011: 6: 474, 12 (zu 9:122); Māturīdī 2005-2011: 7: 455, 12 f. (zu 14:2); Māturīdī 2005-2011: 8: 36, 5 ff. (zu 15:44); Māturīdī 2005-2011: 8: 237, 4 ff. (zu 17:12); Māturīdī 2005-2011: 9: 90, -4 ff. (zu 18:77); Māturīdī 2005-2011: 9: 165, -4 ff. (zu 19:83); Māturīdī 2005-2011: 14: 139, 12 ff. (zu 51:22); Māturīdī 2005-2011: 15: 291, apu. ff. (zu 67:4).

44 Vgl. Ta’wīlāt Māturīdī 2005-2011: 6: 284, 7 ff. (zu Sure 9:3) oder Māturīdī 2005-2011: 8: 176, -4 (zu 16:90).

45 Näheres dazu in TG: 2: 48.

46 Das in der späteren exegetischen Literatur erhaltene Material ist zusammengetragen bei Muḥammad 'Abdarrahīm, Ḥasan al-Bașrī 1992: 1: 61 ff.

47 Diese Formulierung ist von G. Schoeler in die Islamkunde eingeführt worden, in: Schoeler 1996: 41 f., Anm. 109); ähnlich, aber etwas ausführlicher auch in der englischen Fassung des Buches: The genesis of literature in Islam. From the aural to the read (Schoeler, 2009: 76). Sie stammt von Werner Jaeger und bezog sich ursprünglich auf das Werk des Aristoteles (Jaeger, 1912: 147).

48 Zu ihm Huatịb al-Baġdādī 1931: 12: 108 f. nr. 6548; er starb dort im hohen Alter von 93 Jahren am Sonntag, dem 22. Ǧumādā II 253/ 30. Juni 867 und wurde am darauffolgenden Tag zu Grabe getragen. Er war Iraner und vermutlich der Sohn eines Neophyten, der bei der Konversion den Namen Muslim angenommen hatte. Die Gegend von Țūs, nach der er in Bagdad benannt wurde, war den Irakern bekannt, weil dort seinerzeit Hārūn ar-Rašīd auf seiner Iranreise gestorben war. Das Todesjahr ist auch bei Ibn Ḥağar verzeichnet (Ibn Ḥağar, 1907-1909: 7: 372 f.); jedoch bringt dieser daneben noch das Jahr 260/874, wohl als Bezeichnung der Dekade. Dahabī hat demgegenüber 263/ 877 (Dahabī, 1955: 548, 5 ff.); das ist vermutlich ein Irrtum. Țabarī nennt ihn mehrfach in seinem Ta'rīh als seinen unmittelbaren Gewährsmann (Ṭabarī, 1879-1901: 1: 2131, 6; 3075, 16; 3335, 12).

49 Vgl. die riwāya in der Einleitung zu Ta'labīs al-Kašf wal-bayān, Ta'labī 1984: 49, 5 ff. In der Edition des Gesamtwerkes, die Abū Muḥammad Ibn 'Āšūr erstellt hat (1-10, Ta'labī 2002), ist Așamm zu al-Ahtam verlesen. Așamms Kommentar läuft unter der Bezeichnung tafsìr Ibn Kaisān. Hat Muḥammad aṭ-Ṭūsī dieses Exemplar (oder eine seiner Abschriften, die in šĩ itische Kreise gelangte) zur Hand gehabt? 
späteren Sinne, in dem der Koran Vers für Vers besprochen wird, ist Așamms "Buch" vermutlich nie gewesen. Auch der Zweck des Unternehmens ist vielleicht nicht überall und jederzeit in gleicher Weise gesehen worden. Anfangs mag die Kompilation sich mit einem missionarischen Impetus verbunden haben. Bașra war ja eines der Heerlager gewesen, von denen aus die Eroberung und Neuordnung Irans vorangetrieben wurde. Auch Kūfa war eine solche Garnison; von dort aus sind in der zweiten Hälfte des 2. Jh. in zunehmendem Maße Anhänger des Abū Hanīfa in den Osten gegangen. ${ }^{50}$ Sie hofften, als Juristen sich nützlich machen zu können. Wir wissen, daß auch Așamm als „freischaffender" Jurist hervorgetreten ist. ${ }^{51}$

Aber daß dies der Grund gewesen wäre, aus dem seine Schüler die von ihm gehörten exegetischen Bemerkungen sammelten, ist gar nicht gesagt. Zwar stützte man sich in Bașra wie in Kūfa, wenn man als Jurist einen Text zugrunde legte, im 2. Jh. meist nur auf den Koran; das Hadīt war noch keine maßgebliche Autorität. Jedoch ist in den Fragmenten aus Așamms Werk, die uns bei Māturīdī erhalten sind, von juristischen Dingen kaum die Rede. Es geht vielmehr ganz pragmatisch um das Verständnis des Textes. Das war es, was man im Osten brauchte. Man hatte sich dort zwar ohne viel Umstände dem Islam anheim gegeben; aber an die neue heilige Schrift mußte man sich erst einmal gewöhnen. Nur einem Araber trat der Koran „in einer klaren Sprache“ (bi-lisānin mubinn) ${ }^{52}$ entgegen; ein Neophyt dagegen brauchte Hilfe. ${ }^{53}$ Așamm hatte im Irak zu der Generation gehört, die - wie etwa Kisā'ì (gest. 187/803) mit seinem Mutašābih alQur'ān, Farrā' (gest. 207/822) mit seinen Ma'ānī al-Qur'ān oder Abū 'Ubaida (gest. 210/825) mit seinem Mağāz al-Qur'ān - den Text mit sprachlicher Kompetenz zu erschließen versuchten. Er war ein Literalist ${ }^{54}$ und hatte noch nicht den Eindruck, sich gegen eine Vielzahl von Meinungen durchsetzen zu müssen. Erst Māturīdī hat seinen Interpretationen manchmal ein wa-llāhu a' lam entgegengesetzt. ${ }^{55}$

Letzteres hängt natürlich damit zusammen, daß Māturīdī bei Așamm i`tizāl am Werke sieht. ${ }^{56}$ Aber die Schüler erregten mit dieser Tendenz offenbar noch keinen Anstoß; ebensowenig gibt es Anzeichen dafür, daß sie in diesem Sinne

50 Vgl. TG: 1: 200 ff. und 2: 534 ff.; umfassend Madelung 1982: $32 \mathrm{ff}$.

51 TG: 2: $414 \mathrm{ff}$.

52 Sure 26:195; vgl. auch Sure 16:103.

53 Zur Situation jetzt Zadeh 2012: 35 ff.; von Așamm ist dort allerdings kaum die Rede (vgl. S. 80 und 455), und gar nicht von seinem Tafsìr.

54 So El Shamsy 2013: 185.

55 Vgl. etwa Māturīdī 2005-2011: 8: 144, 2 (zu 16:68), 303, 6 (zu 17:58), 9: 73, 5 (zu 18:52) oder 14: 180, ult. ff. (zu 52:37).

56 Näheres s. u. Anm. 80-81. 
missionarisch tätig gewesen seien. Māturīdī urteilt aus späterer Perspektive. Gewiß teilte Așamm manche Positionen, die für die Mu'tazila charakteristisch wurden, vor allem auf dem Gebiet des liberum arbitrium. Aber ebenso wie sein kūfischer Zeitgenosse Dirār b. 'Amr gehörte er zu jener Zwischengeneration, welche die von Wāṣil b. 'Ațā' gegebenen Anstöße zwar aufnahm, aber noch in anderer Weise verarbeitete als später Abū l-Hudail oder Bišr b. al-Mu'tamir. Damit überschritt er für die Leute im Osten noch nicht die Schwelle zur Ketzerei. Für die mu'tazilitische Tradition war auch nicht er derjenige, der Hasan al-Bașrīs Tafsīr weiterführte, sondern 'Amr b. 'Ubaid. Von diesem aber nimmt Māturīdī gar keine Notiz. 'Amrs Rezension ist offenbar früh verloren gegangen - was vermutlich heißt, daß sie in der „Schule“ keine Aufmerksamkeit mehr fand. Für Așamms Art, den Koran auszulegen, scheint Ähnliches $\mathrm{zu}$ gelten; auch er fand unter $\mathrm{Mu}$ 'taziliten bald kaum noch Fürsprecher. Wir hören es deutlich bei Naẓzām:

Begebt euch nicht in die Hände vieler unter den Exegeten, auch wenn sie vor dem breiten Volk (al-'āmma) den großen Mann spielen und auf jede Frage eine Antwort wissen. Viele von ihnen reden grundloses Zeug ohne Gewähr, und je dunkler (oder: merkwürdiger) ein Exeget sich vor den (Leuten) ausdrückt, desto lieber ist er ihnen. 'Ikrima, Kalbī, Suddī, Ḍaḥhāk, Muqātil b. Sulaimān und Abū Bakr al-Aṣamm sollten dabei für euch in ein und dieselbe Kategorie gehören. ${ }^{57}$

Aṣamm ist also für Naẓzām noch ein Mann der alten Zeit. Was Naẓzām vermißt, ist anscheinend ein durchgehendes Konzept. Așamm interpretiert jede Stelle für sich. Er nutzt dabei seinen gesunden Menschenverstand; aber es liegt ihm nicht daran, den Text einer rationalen Gesamtsicht unterzuordnen. An ein „Ethos“ des Korans denkt er nicht; er geht vielmehr „atomistisch“ vor, Vers für Vers einzeln behandelnd, wie dies auch all die anderen taten, die Naẓāām mit ihm nennt. Ǧubbā'ì (gest. 303/915) hat ein Jahrhundert später offenbar ähnlich geurteilt. ${ }^{58}$ Er ist dann auch der erste Mu'tazilit, von dem wir wieder einen Korankommentar

57 Ǧāḥiz 1938-1958: 1: 343, 5 ff.; Naẓāām bringt daraufhin mehrere Beispiele für abstruse Auslegungen, die aber nicht einem bestimmten Exegeten zugeordnet werden (also auch nicht unbedingt von Așamm stammen).

58 TG: 2: 403 f.; er hat den Tafsìr des Așamm gekannt (Nabhā, 2006: 19; auch 67, zu Sure 6: 68). 59 Vgl. Gimaret 1994. Der Šìi 'it 'Alī b. Mūsā Ibn Ṭāwūs (gest. 664/1266), ein Zeitgenosse des Mongoleneinfalls, verfügte noch über ein aus zehn "Bänden” ( $(\check{g} \check{z} \bar{a}$ ') bestehendes Exemplar, das vielleicht schon zu Lebzeiten Ğubbā'îs geschrieben worden war (vgl. Kohlberg, 1992: 342 und Gimaret, 1994: 29). Bemerkenswert ist, daß in der Hauptmoschee von Peking bis vor einigen Jahren ein (vollständiger?) Codex des Werkes aufbewahrt wurde; jedoch ist er mittlerweile nicht mehr auffindbar. 
kennen; ${ }^{59}$ aber auf Așamm greift er kaum zurück. Im Irak ist die Tradition von Așamms Kommentar anscheinend schon zu Beginn des 3. Jh. H. abgebrochen. Es hat offenbar auch nie zwei „Rezensionen“ seines Werkes gegeben wie etwa bei dem Tafsīr des Muqātil b. Sulaimān. ${ }^{60}$ Ǧubbā'ī wird dann von Māturīdī kaum zur Kenntnis genommen; sein Name taucht in den Ta'wīlāt nur an zwei Stellen auf. ${ }^{61}$ Der einzige mu'tazilitische Koranexperte, der in den Ta'wīlät häufiger herangezogen wird, ist Ğa'far b. Ḥarb (gest. 236/850), ein Vorgänger Ğubbā'īs. ${ }^{62}$ Aber er scheint nie einen direkten Tafsïr verfaßt zu haben; gemeint ist wahrscheinlich sein K. Mutašābih al-Qur'ān, das in der Tat über längere Zeit erhalten blieb. ${ }^{63}$

Die genannte riwāya im Vorwort von Ta'labīs al-Kašf wal-bayān scheint keinen Mu'taziliten zu enthalten. Nach dem Mann aus Ṭūs folgen Namen, die uns nicht viel sagen: al-Faḍl b. 'Abbās b. Mihrān > Muhammad b. 'Abdallāh al-qā $\mathfrak{d}^{-64}>$ Abū Sahl Muhammad b. Muhammad b. al-Aš'at aṭ-Ṭālaqānī ${ }^{65}>$ Abū 1-Qāsim al-Ḥasan b. Muhammad b. Ğa'far an-Naisābūrī. Man ist versucht, den letzten Tradenten mit Ibn Ḥabīb an-Naisābūrī (gest. 406/1016) gleichzusetzen, dem Verfasser der 'Uqalā' al-maǧānīn, ${ }^{66}$ der an Ta'labī (gest. 427/1036) mehrere Werke weitergegeben hat, u. a. den Tafsīr des Muqātil b. Sulaimān. ${ }^{67}$ Aber dann müßte man $b$. Ğa'far in $b$. Habib ändern ${ }^{68}$ oder in $b$. Hasan. ${ }^{69}$ In

59 Vgl. Gimaret 1994. Der Šìit 'Alī b. Mūsā Ibn Ṭāwūs (gest. 664/1266), ein Zeitgenosse des Mongoleneinfalls, verfügte noch über ein aus zehn "Bänden” ( $a \check{g} z \bar{a}$ ') bestehendes Exemplar, das vielleicht schon zu Lebzeiten Ğubbā'īs geschrieben worden war (vgl. Kohlberg, 1992: 342 und Gimaret, 1994: 29). Bemerkenswert ist, daß in der Hauptmoschee von Peking bis vor einigen Jahren ein (vollständiger?) Codex des Werkes aufbewahrt wurde; jedoch ist er mittlerweile nicht mehr auffindbar.

60 Eine horāsānische (in Balh) und eine irakische (in Bagdad); vgl. TG: 2: 519 ff. Die irakische hängt dabei anscheinend von Qatāda (gest. 117/735) ab, dem Schüler des Ḥasan al-Bașrī (frdl. Mitteilung von M. Akpinar).

61 Māturīdī 2005-2011: 9: 57, apu. f. und 12: 294, 6 f.

62 Vgl. den Index, Māturīdī 2005-2011: 18: 197.

63 Vgl. TG: 6: 288 nr. 3; auch Sezgin 1967: 619.

64 Goldfeld identifiziert ihn mit einer im Tahdīb at-Tahdīb des Ibn Ḥağar genannten Person dieses Namens, die aber schon 260 gestorben sein soll, also etwa zur gleichen Zeit wie 'Alī b. Muslim aț-Ṭūsī, von dem die Überliefererkette ausgeht. Das ist sehr unwahrscheinlich; die Namenfolge ist ungemein häufig.

65 Die Edition von Ibn 'Āšūr (o. Anm. 49) fügt hier noch die Nisbe al-Anmārī hinzu.

66 Brockelmann 1937-1949: S 1: 254; auch Sezgin 1967: 47 und Kaḥhāla 1975-1980: 3: 278.

67 TG: 2: 520.

68 Allerdings war Ḥabīb wohl nur der Ahnherr der Familie; auf ihn bezieht sich wahrscheinlich auch die Nisbe al-Ḥabībī, die den Namen sonst begleitet.

69 So geht nämlich Ibn Ḥabīb an-Naisābūrīs Genealogie hinter „Ḥasan b. Muhammad“ weiter. 
jedem Fall haben wir es hier mit einem Exemplar zu tun, das sich in Nēšāpūr befand und darum Māturīdī nie zu Gesicht gekommen ist.

Auch spätere $M u^{\prime}$ taziliten haben Așamms Werk nicht mehr zur Kenntnis genommen. Das gilt für den Qāḍī 'Abdalğabbār (gest. 415/1025) ebenso wie vorher schon für Ibn al-Ḩallāl al-Bașrī (gest. nach 377/988), der in seinem $K$. ar-Radd 'alā l-Ǧabrīya al-Qadarīya sich mit deterministischer Exegese auseinandersetzt und seine Gegner dabei nicht nur Ğabriten, sondern auch - in Umkehrung des üblichen Wortgebrauches - „Qadariten“ nennt. ${ }^{70}$ Letzterer schließt sich stattdessen an Ǧa'far b. Harb und Ǧubbā' $\overline{1}$ an. ${ }^{71}$ Aber gerade dies war es, was Leuten wie Māturīdī missfiel. Explizites Mu'tazilitentum fand in Samarqand wenig Anklang. Așamm dagegen war verhältnismäßig neutral; das religiöse Bekenntnis hatte für ihn noch nicht im Vordergrund gestanden. ${ }^{72}$ Natürlich hatte er seine qadaritischen Präferenzen, und man notierte sie auch; aber Māturīdī ging im allgemeinen mit leichtem Tadel darüber hinweg. In TG II 396 habe ich einmal vermutet, dass er der Ibādīya nahestand; aber davon ist in den hier gesammelten Fragmenten nichts zu merken. ${ }^{73}$ Im übrigen erscheint Aṣamm bei Māturīdī unter verschiedenen Namen. Der laqab wird meist von der kunya begleitet: „Abū Bakr al-Așamm“.74 Aber an einigen Stellen steht auch allein „Abū Bakr“, ${ }^{75}$ und statt al-Așamm findet sich häufig die Nisbe „alKaisānī“, auch sie meist mit der kunya,$^{76}$ aber manchmal auch ohne sie. ${ }^{77}$ Das

70 Dazu TG: 6: 288.

71 Näher dazu Mourad 2007: $81 \mathrm{ff}$.

72 Ich halte es darum für wenig wahrscheinlich, daß, wie Altaş 2013: 62 annimmt, Rāzī den Tafsīr Așamms mit weiteren mu'tazilitischen Werken in Hwwārazm kennenlernte, wo er sich in seiner Jugend aufhielt (vgl. van Ess, 2011: 1061). Zwar gab es dort eine fortdauernde mu'tazilitische Tradition; jedoch wurde Așamm nicht primär als Mu'tazilit wahrgenommen, und für die Mafātīh al-ġaib ist der Aufenthalt in Hwwārazm ohnehin zu früh.

73 Es stimmt wohl auch nicht; die Stelle in den Bașā'ir wad-dahăàir des Tauhīdī, auf die ich mich bezog, wird in der Edition von W. al-Qāḍi anders - und einfacher - restituiert; Ibā dīya in der Edition Kailānī wird dort kommentarlos als Imāmìya gelesen (Tauhīdī, 1964-1965: 5: = guz' 9, S. 195 f. nr. 662). Es gehört damit nicht mehr zu Aṣamm, sondern zu Hišām b. al-Ḥakam, der ja Šìi it war (wenn auch noch nicht Imāmit). Așamm erhält gar kein Prädikat. Vgl. Übersetzung und Kommentar der Stelle in TG: 5: 79 (Text IV 23).

74 So z. B. Māturīdī 2005-2011: 1: 48, 5; 2: 249, pu.; 3: 146, 4 usw.

75 So Māturīdī 2005-2011: 2: 20, 1; 5: 363, 3; 6: 76, 4; 8: 123, 9 und 184, -4 usw.; vgl. „Abū Bakr al-mulaqqab bil-Așamm“ in 3: 328, 2 ff.

76 „Abū Bakr al-Kaisānī“; so etwa Māturīdī 2005-2011: 3: 355, 6; 4: 148, 6; 5: 13, 13 sowie 107, $12 \mathrm{f}$. und 255, 4; 14: 172, 9 usw.

77 So etwa Māturīdī 2005-2011: 2: 349, 5. 
ist neu und wird durch keine andere Quelle gestützt. Worauf diese Nisbe sich bezieht, erfahren wir nicht; ${ }^{78}$ aber an der Identität ist kein Zweifel. ${ }^{79}$

Überraschungen bietet das hier gesammelte Material aus seinem Tafsīr kaum; man wird es noch einmal sichten müssen, wenn auch die Zitate bei Ḥākim alĞišumī erschlossen sind. Așamms Zugehörigkeit zur Mu'tazila wird nur selten hervorgehoben. Das geschieht im übrigen stets vonseiten Māturīdīs; ${ }^{80}$ wie Așamm sich selber einordnete, erfahren wir so nicht. Māturīdī zielt in diesen Aussagen immer auf Așamms Interpretation deterministischer Passagen des Korans; ${ }^{81}$ er hält ihre Umdeutung für gequält ${ }^{82}$ und bezeichnet das Ergebnis manchmal als „Phantasterei“ (hayāl). ${ }^{83}$ Anderswo dagegen hält er sich mit einer Stellungnahme zurück. Daß Aṣamm wie Hasan al-Bașrī eine Gottesschau nur im Paradies für möglich hielt, stört ihn nicht. ${ }^{84}$ Auch wenn Aṣamm die Mondspaltung aus Sure 54:1 in die Zeit des Jüngsten Gerichtes verlegt, ${ }^{85}$ nimmt er damit nur eine Meinung Hasan al-Bașris auf. Es wurde nicht als spezifisch mu'tazilitisch wahrgenommen, ${ }^{86}$ obwohl ihm Naẓzām darin folgte. ${ }^{87}$ Ähnlich bei Sure 16:71, wo Așamm rizq auf die sozialen Unterschiede von Arm und Reich bezog. ${ }^{88}$ Das entsprach zwar dem Sinn der Stelle, ließ aber rizq stärker determiniert erscheinen, als ein späterer Mu'tazilit

78 Vgl. Sam‘ānī 1962-1982: 11: 194 f. nr. 3522.

79 Vgl. Māturīdī 2005-2011: 6: 263, 5 ff., wo zuerst „Abū Bakr al-Kaisānī“ steht und kurz darauf dann „Abū Bakr al-Așamm” (263, pu.). Așamm hieß 'Abdarrahmān b. Kaisān; ein „Kaisān“ war darum vermutlich auch der Ahnherr der Familie. Die bei Sam‘ānī verzeichneten Kaisānīs sind zumeist Ägypter. Im übrigen ist die Nisbe bei Māturīdī in den Handschriften häufig zu Kisā’ verschrieben.

80 Vgl. Māturīdī 2005-2011: 5: 322, 4 f., wo er zu den ahl al-i'tizāl gezählt und gleich hinterher (322, 8) dann auch Ğa 'far b. Harb erwähnt wird; auch Māturīdī 2005-2011: 15: 267, 13 ff., wo er im Verein mit den Mu'taziliten insgesamt (ǧumlat ahl al-i'tizāl) Gegenstand der Kritik ist.

81 Vgl. noch Māturīdī 2005-2011: 8: 32, -5 ff. zu Sure 15:39; 8: 45, 1 zu 15:60; 12: 294, 10 zu $39: 3$. 82 So mit Bezug auf Sure 15:39, wo Gott, wenn er Satan „abirren lässt“ (ag்waitanī), ihn nach Așamms Ansicht nur „geschmäht“ hat, oder mit Bezug auf Sure 15:60, wo Gott das Schicksal von Lots Weib „Vorherbestimmt“ hat (qaddarnā), dies aber nach Așamms Ansicht nur „berichtet“. In Sure 7:179, wo es heißt, dass Gott viele Menschen „für die Hölle geschaffen“

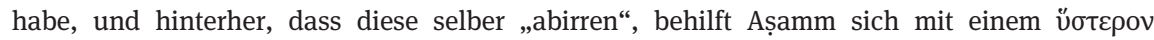

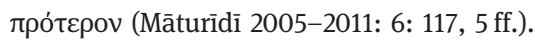

83 So Māturīdī 2005-2011: 8: 196, -4 f. zu Sure 16:104 und 8: 285, ult. zu Sure 17:45, ähnlich auch 8: 186, $8 \mathrm{zu}$ Sure 16:93 (hādā fāsid).

84 Māturīdī 2005-2011: 6: 58, 5 ff. zu Sure 7:143. Mose hat am Sinai Gott sehen wollen, aber dann nur dessen „Zeichen“ wahrgenommen. Gemeint ist der Blitz bzw. der „Donnerschlag“ (aș-șẩiqa; vgl. Sure 2:55 und 4:153), womit Gott den Berg zerschmettert.

85 Māturīdī 2005-2011: 14: 225, 7 ff.

86 Näher dazu TG: 3: 418.

87 Vgl. mein K. an-Nakt des Nazzām, van Ess 1972: 97.

88 Māturīdī 2005-2011: 8: 149, 4 ff. 
es vielleicht verstanden hätte. ${ }^{89}$ Das „Wir werden sie zweimal bestrafen“ in Sure 9:101 nahm Așamm als Beleg für eine vorausgenommene Bestrafung im Grabe; ${ }^{90}$ darin unterschied er sich von seinem Zeitgenossen Ḍirār b. 'Amr (der freilich

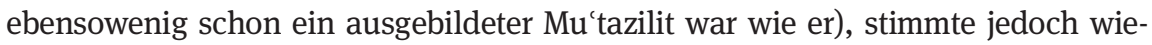
derum mit Ḥasan al-Bașrī überein und nahm auch die vermittelnde Haltung der Generation von Abū l-Hudail und Bišr b. al-Mu'tamir voraus. ${ }^{91}$ Wenn man in Sure 5:3 aus dem Verbot, mit Pfeilen zu losen, per analogiam weiter schloß, daß dann auch Astrologie nicht statthaft sein könne, so wandte er ein, daß die Welt der Sterne doch etwas Anderes sei und Gott uns vielleicht durch sie etwas mitteilen wolle. ${ }^{92}$ Und wenn er bei Sure 14:9 hervorhob, daß nur Gott wissen könne, was alles in der Vergangenheit geschehen sei, ${ }^{93}$ so mag man heraushören, daß Așamm wie manche seiner irakischen Zeitgenossen, vor allem unter den kūfischen Šìiiten (etwa Hišām b. al-Hakam), mit Bezug auf die Zukunft einer solchen Aussage eher ausgewichen wäre; denn wenn Gott die Zukunft nicht kannte, ${ }^{94}$ konnte er sie natürlich auch nicht vorherbestimmen.

Aber damit betreten wir schon wieder unsicheren Boden. Așamm war ein vorsichtiger Mann. Er genierte sich nicht zuzugeben, daß er etwas nicht verstand - so etwa muqit in Sure 4:85; das sei kein Arabisch. ${ }^{95}$ Auch die Bedeutung von nakid $^{a n}$ in Sure 7:58 war ihm unklar. ${ }^{96}$ Muhaimin in Sure 5:48 erkennt er als ein Fremdwort (um dessen Herkunft er sich aber nicht kümmert). ${ }^{97}$ Das Wort muğrim „übersetzt“ er gleich viermal; ${ }^{98}$ es scheint ihm nicht geläufig gewesen zu sein. Wahy „Eingebung“ mit Bezug auf Bienen, die doch keinen Verstand haben, scheint ihm erklärungsbedürftig, ${ }^{99}$ ähnlich wie später dem Qāḍi 'Abdalǧabbār. ${ }^{100}$ Das Gespräch zwischen Kain und Abel in Sure 5:27-29 ist ihm wichtig; es spielte im pazifistischen Diskurs der Zeit eine Rolle. ${ }^{101}$ Aber er

89 Zum Einzelnen vgl. TG: 4: $497 \mathrm{ff}$.

90 Māturīdī 2005-2011: 6: 442, 13 ff.

$91 \mathrm{TG}: 4: 529 \mathrm{f}$.

92 Māturīdī 2005-2011: 4: 148, 6 ff.

93 Māturīdī 2005-2011: 7: 464, 8 ff.

94 Näher dazu TG: 4: $439 \mathrm{f}$.

95 Māturīdī 2005-2011: 3: 365, ult. ff.

96 Māturīdī 2005-2011: 5: 393, 8 f.

97 Māturīdī 2005-2011: 4: 243, $6 \mathrm{f}$.

98 Māturīdī 2005-2011: 7: 188, 2f. zu Sure 11:52; 9: 168, 1 zu 19:86; 12: 141, 9 f. zu 37:34; 17: 120, $11 \mathrm{ff} . \mathrm{zu} 85: 29$.

99 Māturīdī 2005-2011: 8: 143, 2 ff. zu Sure 16:68.

100 'Abd al-Ğabbār 1966: 220, 1 ff. Așamm denkt an eine Art genetischer Programmierung; eine Belehrung ( $t a$ ' lim) ist den Bienen nicht zuteil geworden. Zu wahy im Koran jetzt Neuwirth 2014: 96 f. und 200 f.; auch Neuwirth 2017.

101 Näher dazu demnächst meine „Unfertige Studie“, nr. 6. 
betont, daß auch Kain „gläubig“ gewesen sein müsse; er hätte sonst Gott nicht ein Opfer dargebracht. Abel hatte ihm nur voraus, daß er neben dem Glauben auch Gottesfurcht (taqwā) besaß. ${ }^{102}$ Sure 65:6, wo es heißt, daß man eine Frau, die man verstoßen bzw. „entlassen“ hat, während ihrer Wartezeit nicht aus ihrer Wohnung heraussetzen solle, bezieht er auf Fātima bt. Qais, der eben dies angetan worden war; der Fall war im Hadit aktenkundig geworden ${ }^{103}$ und wurde auf verschiedene Weise entschieden. ${ }^{104^{-}}$

Wir werden annehmen dürfen, daß Așamm gelegentlich Denkmuster und Termini der zeitgenössischen Theologie ins Spiel brachte. Zwar hatte Māturīdī dafür keinen besonderen Geschmack; aber eine Stelle bei Ğāhị deutet in diese Richtung. ${ }^{105}$ Dort liegt offenbar Sure 2:65 oder Sure 5:60 zugrunde; ${ }^{106}$ weder Māturīdī noch Fahraddīn ar-Rāzī haben diese Interpretation aufgenommen. Hadīte dagegen scheinen für seine Exegese kaum Bedeutung gehabt zu haben. $\mathrm{Zu}$ Sure 113:1 behauptet er, ein einschlägiges Prophetenwort zu kennen, das er aber weglassen wolle, weil damit etwas Unziemliches/Unmögliches ausgesagt sei (fíhi mā lā yağūz); ${ }^{107}$ er hält es also für apokryph. ${ }^{108} \mathrm{Im}$ Koran rechnete er mit Abrogation; wir können es allerdings nur für einen einzigen Fall bestätigen. ${ }^{109}$ In Sure 67:27 versucht er sich an einer abweichenden Lesung, die sonstwo nicht bezeugt ist: tadu' 'ūna statt tadda'ūna, also von $d a^{\text {' }} a$ statt von idda' $\bar{a} ;{ }^{110}$ er kommt so $\mathrm{zu}$ einer qadaritisch intendierten Interpretation: "was ihr (Ungläubige) wegstoßt”, also "zurückweist, nicht haben wolltet". "111 In Sure 81:24 entscheidet er sich mit der Mehrheit - und der heute üblichen Lesung -

102 Māturīdī 2005-2011: 4: 200, 7 ff.

103 Vgl. van Ess 2014: $29 \mathrm{ff}$.

104 Māturīdī 2005-2011: 15: 233, apu. ff.; Māturīdī notiert, daß Aṣamm sich hier gegen Šāfi'ī gestellt habe.

105 Ǧāhịiz 1938-1958: 4: 73, -4 ff.; übernommen bei Tauhịdī 1964-1965: 2: 825, ult. ff. = Tauhīdī 1982: 9: 195 f. nr. 662.

106 Es geht um die Frage, ob Gott tatsächlich Menschen in Affen verwandeln kann; Așamm hielt ebenso wie sein Zeitgenosse Hišām b. al-Ḥakam dies für möglich. Vgl. auch die Beispiele, die Nabhā 2006 in seiner Einleitung S. 25-27 unter § 8 bringt.

107 Māturīdī 2005-2011: 17: 386, ult.; gemeint ist wohl das Ḥadīt nach 'Ā'iša, das dort in Anm. 10 genannt wird.

108 Vgl. weiterhin die Ausführungen von Nabhā 2006: 22 f. § 5.

109 Im Verhältnis von Sure 9:122 zu 9:120; vgl. Māturīdī 2005-2011: 6: 474, 12.

110 Das Verb da" $a$ ist im Koran belegt; vgl. Sure 52:13 und 107:2.

111 Im Sinne von „Ihr seid selber schuld“ (Māturīdī, 2005-2011: 15: 322, 5 ff.). Das Problem dieser Interpretation ist, daß der Vers vom Jüngsten Gericht redet; dort steht es den Ungläubigen gar nicht mehr frei, sich für etwas zu entscheiden. 
für danīn statt zanīn. ${ }^{112}$ In Sure 7:42 rechnet er anscheinend mit einem Redaktionsfehler; lā nukallifu nafsan illā wus'ahā gehöre eigentlich zu 7:35 und sei in Vers 42 nachträglich eingeschoben. ${ }^{113}$

Wann die Handschriften von Așamms Kommentar verloren gegangen sind, wissen wir nicht. Wahrscheinlich wird man den Mongoleneinfall verantwortlich machen müssen; Fahraddīn ar-Rāzī, der kurz vorher starb, ${ }^{114}$ ist unser letzter Zeuge. Māturīdīs Ta'wīlāt dagegen wurden zwei Jahrhunderte nach ihrem Entstehen noch einmal Gegenstand eines Kommentars: von 'Alā'addīn Muhammad b. Aḥmad as-Samarqandī (gest. 539/1144), einem Schüler der Brüder Pazdawī (Abū 1-'Usr und Abū l-Yusr) sowie des Abū l-Mu'īn anNasafi. ${ }^{115}$ Dieser Text (= Šarh at-Ta'wīlāt) ist bisher nicht ediert (und verdient dies vielleicht auch nicht); jedoch wird er im Apparat zum Grundwerk gelegentlich herangezogen. Das geschieht auch mit Bezug auf Stellen, an denen Așamm zitiert wird. Jedoch ergeben sich dabei für Așamm keine neuen Erkenntnisse. ${ }^{116}$

Danksagung: Ich danke J. Thomann für tatkräftige Hilfe bei der Umgestaltung des Manuskriptes nach den Richtlinien der Zeitschrift.

\section{Bibliographie}

'Abd al-Ǧabbār b. Ạ̣mad al-Asadābādī (1966): Tanzīh al-Qur'ān 'an al-mațā'in. Bairūt: Dār an-Nahụa al-Ḥadīta.

Altaş, Eşref (2013): „Fahreddin er-Râzî’nin eserlerinin kronolojisi“. In: İslam düşüncesinin dönüşüm çağında Fahreddin er-Razi. Hrsg. von Ömer Türker und Osman Demir. İstanbul: iSAM Yayınları, 91-164.

Badeen, Edward (2008): Sunnitische Theologie in osmanischer Zeit. (Istanbuler Texte und Studien 16). Würzburg: Ergon.

Brockelmann, Carl (1937-1949): Geschichte der arabischen Litteratur. Leiden: Brill.

112 Für zanīn trat man ein in Kūfa ('Alī, Ibn Mas'ūd), aber auch Ibn 'Abbās, Zaid b. Tābit, 'Ā'iša, Muǧāhid usw. (vgl. Khoury, 1990-2002: 12: 368).

113 Māturīdī 2005-2011: 5: 347, 11 ff.

114 Nämlich 606/1210. Die Zerstörung des Reiches der Hูwārazmšāhs durch die Mongolen fällt in die Jahre 616-20/1219-23.

115 Mit seinem juristischen Handbuch Tuhfat al-fuqahā' beeinflußte 'Alā'addīn die Badā'i aṣșanā'i seines Schülers und Schwiegersohnes Kāsānī (vgl. van Ess 2011: 778). Allgemein zu ihm Madelung 1985 und Brodersen 2008.

116 Natürlich gibt es in den Ta'wīlāt auch andere Stellen, die von Interesse sind. In Māturīdī 2005-2011: 2: 78, 2 ff. sagt Māturīdī von den Qarmaten, daß nach ihrer Ansicht der Koran nicht von Gott stamme, sondern von Muhammad. Man wüßte gern, ob 'Alā'addīn sich dazu äußert. Māturīdī hat sich in zwei Traktaten mit den Qarmaten auseinandergesetzt (Götz, 1965: 29). 
Brodersen, Angelika (2008): „Alā' al-Dīn al-Samarqandī”. In: Encyclopaedia of Islam Three. Hrsg. von Gudrun Krämer [et al.]. Leiden: Brill, 2008-2: 54-56.

Dahabī, Muḥammad b. Aḥmad aḍ- (1955-1958): Taḍkirat al-ḥuffāz. Ḥaidarābād: Maṭba'at mağlis dā'irat al-ma'ārif al-'uțmānīya.

El Shamsy, Ahmed (2013): The Canonization of Islamic Law: a Social and Intellectual History. Cambridge: Cambridge University Press.

Faḥr ad-Dīn ar-Rāzī, Muḥammad b. 'Umar (1862-1872): Mafātīḥ al-ġaib. Būlāq: Mu'ǧam almațbū'āt al-'arabīya.

Faḩr ad-Dīn ar-Rāzī, Muḥammad ibn 'Umar (1966): Munāẓarāt fí bilād Mā warā' an-nahr. Hrsg. von Fathalla Kholeif. Beirut: Dar El-Machreq.

Frolow, Dimitry (1997): „Ibn al-Nadīm on the history of Qur'anic exegesis“. Wiener Zeitschrift für die Kunde des Morgenlandes 87: 65-81.

Frolow, Dimitry (2013): „Ibn al-Nadīm on the history of Qur’anic exegesis“. In: Tafsīr: interpreting the Qur'ān. Hrsg. von Mustafa Shah. London: Routledge, Bd., 1, 207-218.

Gacek, Adam (2001): The Arabic Manuscript Tradition. (Handbuch der Orientalistik. Abteilung 1, Der Nahe und Mittlere Osten 58). Leiden: Brill.

Ǧāḥiz̧, 'Amr b. Baḥr al- (1938-1958): Kitāb al-Ḥayawān. Hrsg. von 'Abdassalām Muḥammad Hārūn. Mișr: Mușțafā al-Bābī al-Ḥalabī.

Gimaret, Daniel (1994): Une lecture mu'tazilite du Coran: le "Tafsīr" d'Abū 'Alī al-Djubbā'î (m. 303/915), partiellement reconstitué à partir de ses citateurs. (Bibliothèque de l'Ecole des Hautes Études. Section des sciences religieuses 101). Louvain: Peeters.

Götz, Manfred (1965): „Māturīdī und sein Kitāb Ta’wỉlāt al-Qur'ān“. Der Islam 41: 27-70.

Götz, Manfred (1999): „Māturīdī and his Kitāb Ta’wïlāt al-Qur'ān“. In: The Qur'an. Formative Interpretation. Hrsg. von Andrew Rippin. Aldershot: Ashgate Variorum, 181-214.

Götz, Manfred (2013): „Māturīdī and his Kitāb Ta’wìlāt al-Qur'ān“. In: Tafsìr: interpreting the Qur'ān. Hrsg. von Mustafa Shah. London: Routledge, Bd. 3, 283-313.

Griffel, Frank (2007): „On Fakhr al-Dīn al-Rāzī’s Life and the Patronage he Received“. Journal of Islamic Studies 18: 313-344.

Ḥasan al-Bașrī (1992): Tafsīr al-Ḥasan al-Bașrī. Hrsg. von Muḥammad 'Abdarraḥīm. Al-Qāhira: Dār al-Ḥadīt.

Hațīib al-Bag̉dādī, Aḥmad ibn 'Alī al- (1931): Ta'rīh Bag̉dād. Al-Qāhira: Maktabat al-Hānǧ̄ī.

Ibn Ḥağar al-'Asqalānī, Aḥmad b. 'Alī (1907-1909): Taḥdīib at-Taḥ̂ī̄b. Ḥaydarābād: Maṭba'at Mağlis Dā'irat al-Ma'ārif an-Niẓāmiyya.

Ibn Ḥağar al-'Asqalānī, Aḥmad b. 'Alī (1912): Lisān al-Mīzān. Ḥaydarābād: Maṭba'at Mağlis Dā'irat al-Ma'ārif an-Niẓāmiyya.

Ibn an-Nadīm (2009): Fihrist. Hrsg. von Aiman Fu'ād as-Saiyid. London: Al-Furqān Islamic Heritage Foundation.

Jaeger, Werner (1912): Studien zur Entstehungsgeschichte der Metaphysik des Aristoteles. Berlin: Weidmann.

Jomier, Jacques (1977): „Les Mafatih al-ghayb de l'Imam Fakhr al-Din al-Razi: quelques dates, lieux, manuscrits“. Mélanges de l'Institut Dominicain d'Etudes Orientales du Caire 13: 253-290.

Jomier, Jacques (1980): „Qui a commenté l'ensemble des Sourates al-'Ankabūt à Yãsīn (29-36) dans Le "Tafsīr al-Kabīr" de l'Imām Fakhr al-Dīn al-Rāzî?". International Journal of Middle East Studies 11: 467-485.

Kaḥ̣āla, 'Umar Rị̣ā (1975-1980): Mu'ğam al-mu'allifinn: Tarāğim muṣannifí l-kutub al-'arabiyya. Bayrūt: Dār lḥyā' at-turāt al-'arabī. 
Khoury, Adel Theodor (1990-2001): Der Koran: arabisch-deutsch. Gütersloh: Gütersloher Verlagshaus.

Kohlberg, Etan (1992): A medieval Muslim Scholar at Work: Ibn Ṭāwūs and His Library. (Islamic philosophy, theology and science 12). Leiden: Brill.

Lagarde, Michel (1996): Index du Grand commentaire de Fahr al-Dīn al-Rāzī. (Handbuch der Orientalistik. Abt. 1, Der Nahe und der Mittlere Osten 22). Leiden: Brill.

Madelung, Wilferd (1982): „The early Murji'a in Khurāsān and Transoxania and the Spread of Ḥanafism“. Der Islam 59: 32-39.

Madelung, Wilferd (1985): „'Alā al-Dīn Samarqandī“. In: Encyclopaedia Iranica. Hrsg. von Ehsan Yarshater. London: Routledge, Bd. 1, 782-783.

Māturīdī, Muḥammad b. Muḥammad al- (1971): Tafsīr al-Māturīdī al-musammā Ta'wīlāt ahl assunna. Hrsg. von Ibrāhīm 'Iwaḍain und as-Sayyid 'Iwaḍain. al-Qāhira: al-Mağlis al-A'lā li-šŠu'ūn al-Islāmiyya.

Māturīdī, Muḥammad b. Muḥammad al- (1983): Ta'wìlāt ahl as-sunna al-ma'rūf bi-Ta'wïlāt alQur'ān. Hrsg. Von Muḥammad Mustafị̣ ar-Raḥmān. Bangladesh: al-Mu'assasa al-islāmiyya.

Māturīdī, Muḥammad b. Muḥammad al- (2005-2011): Ta'wìlāt al-Qur'ān. Hrsg. von Bekir Topaloğlu. Istanbul: Mizan Yayınevi.

Mourad, Suleiman A. (2007): „Ibn al-Khallāl al-Bașrī and His Cuvre on the Problematic Verses of the Qur'ān Kitāb al-Radd 'alā al-jabriyya al-qadariyya (Refutation of the Predestinarian Compulsionists)“. In: A Common Rationality: Mu'tazilism in Islam and Judaism. Hrsg. von Camilla Adang, Sabine Schmidtke und David Sklare. Würzburg: Ergon, 81-100.

Mourad, Suleiman A. (2012): „The Revealed Text and the Intended Subtext: Notes on the Hermeneutics of the Qur'ān in Mu'tazila Discourse As Reflected in the Tahđỉb of al-Hākim alǦišumi (d. 494/1101)“. In: Islamic Philosophy, Science, Culture, and Religion: Studies in Honor of Dimitri Gutas. Hrsg. von Felicitas Opwis und David Reisman. Leiden: Brill, 367-395.

Nabhā, Haḍir Muḥammad (2006): Tafsīr Abī Bakr al-Așamm. Beirut: Dār al-kutub al-'ilmiyya.

Neuwirth, Angelika (2014): Scripture, Poetry, and the Making of a Community: Reading the Qur'an as a Literary Text. Oxford: Oxford University Press.

Neuwirth, Angelika (2017): „The 'Discovery of Writing' in the Qur'an“. In: The Qur'an and Adab: The Shaping of Literary Traditions in Classical Islam. Hrsg. von Nuha Alshaar. Oxford: Oxford University Press [im Druck].

Rudolph, Ulrich (1997): Al-Māturīdī und die sunnitische Theologie in Samarkand. (Islamic philosophy, theology and science 30). Leiden: Brill.

Saleh, Walid A. (2004): The Formation of the Classical Tafsir Tradition: the Qur'än Commentary of al-Tha'labī (d. 427/1035). (Texts and studies on the Qur'ān 1). Leiden: Brill.

Sam'ānī 'Abd al-Karīm b. Muḥammad as- (1962-1982): Kitāb al-ansāb. Hrsg. von Abdul Mu'īd Khan. Ḥaydarābād: Mațba'at Mağlis Dā’irat al-Ma'ārif an-Niẓāmiyya.

Schoeler, Gregor (1996): Charakter und Authentie der muslimischen Überlieferung über das Leben Mohammeds. (Studien zur Sprache, Geschichte und Kultur des islamischen Orients. Neue Folge 14). Berlin: de Gruyter.

Schoeler, Gregor (2009): The genesis of literature in Islam: from the aural to the read. (The new Edinburgh Islamic surveys). Übers. von Shawkat M. Toorawa. Edinburgh: Edinburgh University Press.

Sezgin, Fuat (1967): Qur'anwissenschaften - Hadīt - Geschichte - Fiqh - Dogmatik - Mystik. (Geschichte des arabischen Schrifttums 1). Leiden: Brill.

Ṭabarĭ, Muḥammad b. Ǧarìr aț- (1879-1901): Annales = Ta'rịh ar-rusul wa-l-mulūk. Hrsg. von Michael Jan de Goeje. Brill: Leiden. 
Ia 'abī, Aḥmad b. Muhammad aț- (1984): Qur'anic commentary in the eastern Islamic tradition of the first four centuries of the Hijra: an annotated edition of the preface to al-Tha'labi's “Kitāb al-Kashf wa'l-Bayān 'an Tafsīr al-Qur'ān". Hrsg. Von Isaiah Goldfeld. Acre: Srugy. Ia 'abī, Aḥmad b. Muḥammad aț- (2002): Al-Kašf wa-l-bayān. Hrsg. von Abū Muḥammad Ibn 'Āšūr. Beirut: Dār lḥyā' at-turāṭ al-'arabī.

Tauḥīdī, 'Alī b. Muḥammad at- (1964-1965): Al-Bașā'ir wa-dِ-dahāàir. Hrsg. von Ibrāhīm al-Kīlānī. Dimašq: Mațba'at al-Inšā'.

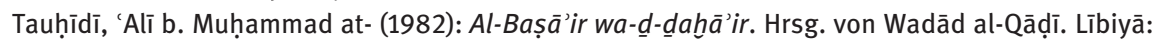
ad-Dār al-'arabiyya li-l-Kitāb.

TG = Ess, Josef van (1991-1997): Theologie und Gesellschaft im 2. und 3. Jahrhundert Hidschra: eine Geschichte des religiösen Denkens im frühen Islam. Berlin: de Gruyter.

van Ess, Josef (1966): Die Erkenntnislehre des 'Aḍudaddīn al-Īcī: Übersetzung und Kommentar des ersten Buches seiner Mawāqif. (Veröffentlichungen der Orientalischen Kommission, Akademie der Wissenschaften und der Literatur, Mainz 22). Wiesbaden: Steiner, 1966.

van Ess, Josef (1972): Das Kitāb an-Nakț des Naẓzām und seine Rezeption im Kitāb al-Futyā des Ğāhiz: eine Sammlung der Fragmente mit Übersetzung und Kommentar. (Abhandlungen der Akademie der Wissenschaften in Göttingen. Philologisch-historische Klasse. Folge 3; Nr. 79). Göttingen: Vandenhoeck und Ruprecht.

van Ess, Josef (2011): Der Eine und das Andere: Beobachtungen an islamischen häresiographischen Texten. Berlin: de Gruyter.

van Ess, Josef (2014): „Neue Fragmente aus dem K. an-Nakṭ des Naẓzām”. Oriens 42: $20-94$.

Zadeh, Travis (2012): The Vernacular Qur'an. Translation and the Rise of Persian Exegesis. (Qur'anic studies series 7). Oxford: Oxford University Press. 